\title{
Espíritu vs. alma espiritual
}

Spirit vs. spirit soul

\author{
Jordi Castellet i Sala ${ }^{1}$ \\ Ateneu Universitari Sant Pacià
}

Recibido: 10.12 .2020

Aceptado: 24.12.2020

\section{Resumen}

El debate en torno a la antropología aborda aquí una cuestión de categorías fundamentales en torno a la estructura básica del ser humano: hombre y mujer, niño y anciano. La terminología articulada por la categoría «espíritu - pneuma» abre las posibilidades de una nueva comprensión ante los retos planteados por las ciencias experimentales, la ética, la moral, incluso la religión. El esquema diádico «cuerpo y alma» se muestra agotado ante los callejones sin salida con los que se ha encontrado al llegar hasta nuestros días. Por este motivo, el artículo defiende poder recuperar la antropología brotando de los datos de la revelación judeocristiana, tomados como auténticos y válidos para vehicular la verdad de la realidad humana. En efecto, resulta necesario recuperar la originalidad de la estructura triádica de espíritu, alma y cuerpo, presentada por el apóstol Pablo, de forma totalmente inesperada en su primera carta a los Tesalonicenses (1Te 5,23).

Palabras clave: Antropología triádica, espíritu, alma espiritual, cuerpo.

1jordi.castellet@guifi.net https://orcid.org/0000-0002-3280-878X 


\begin{abstract}
The debate around anthropology here addresses a question of fundamental categories around the basic structure of the human being: man and woman, child and old man. The terminology articulated by the category «spirit - pneuma» opens the possibilities of a new understanding in the face of the challenges posed by the experimental sciences, ethics, morals, even religion. The «body and soul» dyadic scheme is exhausted in the face of the dead ends that it has encountered in reaching our days. For this reason, the article defends being able to recover anthropology springing from the data of the Judeo-Christian revelation, taken as authentic and valid to convey the truth of human reality. Indeed, it is necessary to recover the originality of the triadic structure of spirit, soul and body, presented by the apostle Paul, in a totally unexpected way in his first letter to the Thessalonians (1Th 5,23).
\end{abstract}

Key words: Thryadics, Anthropology, Spirit, Spiritual Soul, Body.

\title{
1. Planteamiento
}

La cuestión que se intentará dilucidar en las siguientes páginas tratará de proyectar un poco de luz sobre la posibilidad de expresar los términos de la antropología fundamental, ya sea en base de la expresión «alma espiritual», ya sea en base del término «espíritu». La primera posibilidad suele articular una antropología en base diádica, cuerpo y alma; tomando sus raíces en los escritos de Platón (+347 aC) y Aristóteles (+322), reinterpretados por Tomás de Aquino (+1274). La segunda, articula una antropología en base triádica, espíritu, alma y cuerpo, que arranca en la Escritura bíblica, que cristaliza en el apóstol Pablo (ca. +68 dC), en su carta a los de Tesalónica, en medio de un discurso de tono marcadamente escatológico: «Que el Dios de la paz os santifique totalmente; y que todo vuestro ser, el espíritu, el alma y el cuerpo, se mantenga irreprochable para la parusía de nuestro Señor Jesucristo» (1Te 5,23). Una formulación triádica que alcanza las cotas más altas en Padres de la Iglesia como Ireneo de Lyon (+202) en su clásico «Adversus Haereses», que sobrevuela a lo largo de la presente exposición: «la unión y la mezcla del [cuerpo, el alma y el espíritu] constituyen al hombre 
perfecto-téleios. $»^{2}$ El mismo Orígenes de Alejandría (+254) en su breve pero denso «Diálogo con Heráclito» retoma la temática, reproducida en obras como en su «Sobre los principios»:

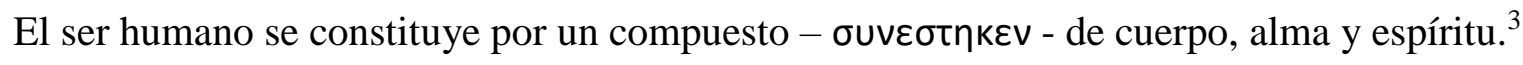
Un ser compuesto, como explican con certitud las santas escrituras ${ }^{4}$ [en 1 Te 5,23]. ${ }^{5}$

Está claro de todos modos que este espíritu no es el Espíritu Santo sino una parte del compuesto humano, tal y como lo enseña el Apóstol, cuando dice: «el Espíritu mismo da testimonio a

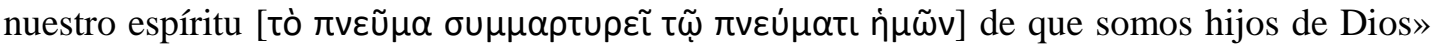
$(\mathrm{Rm} 8,16)$. Si se tratara del Santo Espíritu, no diría: «el espíritu da testimonio a nuestro espíritu.» Así pues, nuestro Salvador y Señor, en su voluntad de salvar a la humanidad, quiso salvar el cuerpo, de semejante manera que había querido salvar el alma y quiso salvar lo que en él quedaba: el espíritu. ${ }^{6}$

A pesar de contar con una tradición bien arraigada y fundamentada, que aquí sólo se ha esbozado en este inicio de introducción, en cambio resultará que, en el curso de la historia, enseguida el platonismo y el neoplatonismo tomarán ventaja. En consecuencia, la formulación de la antropología triádica quedará como escondida bajo la articulación diádica, reanudada en nueva factura por el Aquinate y, al menos en el ámbito eclesiástico, universitario y filosófico, flotará por encima, llevándose el premio de la concesión de la expresión de la estructura básica del ser humano.

Sin embargo, en este artículo se quiere mostrar cómo esta misma articulación diádica ha tocado techo, después de los giros de la historia, y ha terminado por agotar su posibilidad de continuar poder expresando la totalidad del ser humano. En efecto, hoy en día, la afirmación

\footnotetext{
${ }^{2}$ Cf. Ireneo de Lyon, $A H$ V.6,1: SCh 153, 72-81.

${ }^{3}$ Orígenes, Íd., Dial.Herac. VI: SCh 67, 68-69 = Íd., PA IV.2,4.11: GCS V.313,2 = SCh 268,312-313 =FBM $310,146=$ LAIA 49,362-364

${ }^{4}$ Orígenes, Dial. Herac. 5,26-6,22: SCh 67,68-69.

${ }^{5}$ Sobre 1Te 5,23, base escripturística de la doctrina tricotómica, cf. Orígenes, Comm. Mat. 13,2. Íd.,: Comm. Rom. 1,10: PG 14,856 A. Para la aplicación de la tricotomia al Cristo encarnado Íd., PA II.8,4.

${ }^{6}$ Orígenes, Dial. Herac. 6,23-7,20: SCh 67,70-71.
} 
como cuerpo y alma, ${ }^{7}$ de hecho, se está limitando a su ámbito más material, físico y biológico. De hecho, las corrientes materialistas del siglo XIX, que han entregado sus más amargos frutos en el XX, acaban contemplando al ser humano como puramente material, donde la mente, y por consiguiente el alma, no son sino emergencias de la misma materia, como una pura evolución de la física pura. Para los materialistas monistas del siglo XX, y siguiendo el principio de la navaja de Occam, «entia non sunt multiplicanda praeter necessitatem», no es necesario postular otro órgano distinto, a saber, el alma, si se puede comprender la naturaleza humana con una estructura más simple y básica como es la materia en sí, más fácil de manejar y comprender; al menos aparentemente.

Pero incluso cabe reconocer como este punto de vista queda excluido de la certeza, ya que son los mismos físicos los que se preguntan hoy sobre la entidad de la materia, tal como recuerda un especialista del CERN de Ginebra, Carlo Rovelli: «Cuanto más nos fijamos en los detalles diminutos de la materia, más estructuras profundas observamos. ${ }^{8}$ Para todas las cuestiones científicas, sean experimentales o humanas, hay una actitud básica de humildad, a partir del principio socrático de la docta ignorancia, que practica el mismo autor, declarándose agnóstico o, directamente, ateo:

La ciencia nace de este acto de humildad, de no fiarse ciegamente de nuestras intuiciones. No fiarse de lo que todos dicen. No fiarse del conocimiento acumulado por nuestros padres y abuelos. Nada aprendemos si pensamos que ya sabemos lo que es esencial, si creemos que lo esencial se encuentra ya escrito en un libro o custodiado por los ancianos de la tribu. Los siglos en que los hombres han tenido fe en lo que creían son los siglos en que todo permaneció inmóvil y nadie aprendió nada nuevo. Si hubieran tenido fe ciega en el saber de sus padres, Einstein, Newton y Copérnico no habrían puesto nada en duda ni habrían hecho avanzar nuestro saber. ${ }^{9}$

Vivir en la incertidumbre es difícil. Algunas personas prefieren una certeza cualquiera, aunque

${ }^{7}$ Catecismo de la Iglesia Católica [CEC] 362-368.

${ }^{8}$ ROVELLI, La realidad no es lo que parece. ÍD., Set breus lliçons de física.

${ }^{9}$ ÍD., La realidad no es lo que parece, 234. 
sea claramente infundada, a la incertidumbre que genera la conciencia de nuestros límites. Hay quien prefiere creer lo que sea sólo porque lo creían los ancianos de la tribu, sin importarle si es verdadero o falso, sin tener el valor de ser sincero y aceptar que vivimos sin saber todo lo que quisiéramos saber. ${ }^{10}$

Los materialismos monistas han acabado cristalizando en la ideología del actual posthumanismo, ${ }^{11}$ donde se pierde de vista la dignidad humana intrínseca a la persona. En este paso, que se da entre lo humano y lo que no lo es, se pasa a un estadio donde la persona se vuelve equivalente de los animales y, por ende, los más serviles. ¡Harari compara las personas con los cerdos! En consecuencia, resulta bien evidente y precisa la pretensión de la antropología triádica, mostrando cómo estos resultados de carácter intelectual, científico, incluso moral y espiritual, no son sino frutos de un planteamiento diádico, forjado en pleno siglo XIII con santo Tomás de Aquino. Si bien la tradición de la estructura cuerpo y alma es mucho más antigua, tal vez incluso de una edad similar a la del planteamiento triádico, ésta en cambio, pertenece y arranca de la Escritura; es decir, de la revelación. Por el contrario, la tradición de la estructura diádica arranca de la filosofía griega antigua y de la pura y noble potencia del pensamiento humano. Así, pues, si bien ambas detentan todo el derecho de existir, aquí se parte de la afirmación, basada en una convicción de agotamiento del planteamiento diádico, que esta presentación ha tocado techo, que ha quedado agotada, entregando sus frutos más amargos, en forma de deshumanización. En cambio, la estructura triádica disfruta ante sí aún mucho camino por recorrer, por lo que se puede albergar la esperanza que acaben dando respuesta a los interrogantes y misterios del humano contemporáneo.

Este debate, expresando ampliamente en mi tesis doctoral, ${ }^{12}$ así como en multitud de artículos

\footnotetext{
10 Íbid., 236.

${ }^{11}$ Para una aproximación al posthumanismo: TORRALBA, Humanisme, transhumanisme i posthumanisme, donde el autor se apunta a una relectura actualitzada de la propuesta de los cibernéticos y mecanicistas a propósito de otra obra reciente: BOSTROM, «A history of transhumanist thought». Anteriormente fue Ruiz de Gopegui quien fue debatido en sus postulados por RUIZ DE LA PEÑA, Las nuevas antropologías, 133-199. Últimamente parece que abundan ensayos en este sentido como el del famoso autor Yuval Noah HARARI, Homo Deus. Una breu historia del demà, una obra esta estudiada y comentada a propósito en un artículo de mi propia factura: CASTELLET I SALA, «Homo Deus o l'home creat a si mateix».

12 ÍD., Esperit, anima i cos: antropologia primera triàdica seguint Michel Fromaget y su excerpta.
} 
propios, ${ }^{13}$ quiere dilucidar aquí la cuestión de la propiedad y pertenencia de la nomenclatura del «espíritu» por encima de la de «alma espiritual», esta última mucho más reciente y, en resumen, mucho menos afortunada.

En efecto, pues, los retos planteados por las corrientes materialistas del siglo XIX y XX han hecho aflorar concepciones reductivas de la antropología que llegan hasta el posthumanismo, un verdadero reto tanto para los humanistas como para los ateos. Para las corrientes antropológicas actuales, parece como si ya no importara la dimensión espiritual de la persona humana, como si se tuviera que dejar de lado el hablar no sólo del alma, sino sobre todo del espíritu. Los descubrimientos deslumbrantes de la ciencia, en los ámbitos de la psicología y de la neuropsicología, han provocado una reducción del ser humano al ámbito más materialista, por mucho que los físicos hesitan sobre la calidad de la misma materia, convertida y comprendida a fin de cuentas como mera energía. El reductivismo a la simple materia, aunque misteriosa para el mundo de la física, por una parte, se sitúa junto a otro tipo de reductivismo; en este caso postulando el cerebro como órgano visible, físico, estudiable y cognoscible. De todas formas, y como reconocen los mismos neurobiólogos, el cerebro sigue siendo el gran desconocido del cosmos. ${ }^{14} \mathrm{El}$ alma aparece, como resultado del turbulento chasquido de ideas acumuladas a finales del siglo XX, como algo incomprensible e innecesario. Como conclusión no escrita de esta concepción posthumanista y materialista práctica, se llega a afirmar que no se tiene que hablar del alma, porque hablando del cerebro ya resulta suficiente y demasiado. Cierto es que el científico y el filósofo que se llevan hoy son aquellos que, por sobrante, no admiten de entrada una dimensión humana más allá de la física y material; se llame precisamente «alma»o «espíritu», tanto da.

Sin embargo, correlativamente a estos, otros corrientes antropológicos continúan solicitando una múltiple dimensionalidad del ser humano que vaya más allá de la estricta materialidad física y del puro psiquismo reductor. Especialmente en el ámbito de las ciencias médicas, del acompañamiento y asistencia de las personas en el umbral de la vida y de la muerte, se solicita

13 ÍD., «Homo Deus o l'home creat a si mateix» ÍD., «Esperit, ànima i cos. Introducció a l'antropologia».

${ }^{14}$ ACARÍn TUSELL, El cerebro del rey: vida, sexo, conducta, envejecimiento y muerte. 
un reconocimiento de la dimensión espiritual que permanezca escondida en los límites de la existencia, como en estado mortecino. Jacquemin se formula esta cuestión a la hora de plantear los testamentos vitales, dice:

Hemos definido recientemente la vida espiritual como un movimiento de existencia. ${ }^{15}$ Estamos convencidos de que el ser humano es un todo y, por tanto, calificamos la espiritualidad como tal, [... entendida como] la vida humana, la nuestra, es una historia, un lugar de cambio que cada uno lleva en relación con el otro y con el mundo y que, en toda ocasión, lo precede de alguna manera. Este movimiento se encuentra constituido por tres o cuatro dimensiones intrínsecamente relacionadas y en constante interacción: el cuerpo, la dimensión psíquica, la dimensión ética como punto de vista del bien para la vida y la dimensión religiosa-trascendente para ciertas personas. [...] Esta esquematización toma por objetivo volver visible la dimensión espiritual de la existencia, del cuidado ${ }^{16}$ y de la reflexión ética inscrita en la dimensión subjetiva de la acción. ${ }^{17}$

Así, pues, como se ve, la pregunta aflora una y otra vez: ¿realmente, la antropología, diádica, cuerpo y alma, presentada actualmente y de forma mayoritaria por la Iglesia, continúa siendo la más adecuada para afrontar los nuevos retos antropológicos? De hecho, junto con los materialismos estériles, continúan emergiendo las preguntas sobre la multidimensionalidad del ser humano, que puede respetar mejor su naturaleza en todas sus dimensiones sin excepción. Habrá, pues, que avanzar en nuestra exposición, para intentar articular un lenguaje fundamental y unas categorías adecuadas que respondan a lo que el ser humano es en sí; más allá de la tentación de los materialismos y reduccionismos, para los que siempre habrá tiempo, pero que en ningún caso respetarán la justicia del ser humano en su integridad triádica, es decir en su realidad pneumo-psico-somática.

\footnotetext{
${ }^{15}$ JACQUEMIN, QUAND l'autre souffre. Éthique et spiritualité.

${ }^{16}$ Nouwn, Prendre soin les uns des autres. Une spiritualité $d u$ «care».

${ }^{17}$ JACQUEMIN, «Directives anticipées et récit de vie», 9.
} 


\section{Siete premisas sobre los términos «alma espiritual» y «espíritu»}

Para tratar de dilucidar la cuestión, se plantean a continuación unas observaciones aportadas para el debate en torno a la terminología según su categoría ontológica. Por una parte, un apartado en torno a la terminología «alma espiritual», que representa el paradigma diádico; por otra parte, en torno a la categoría de «espíritu», que abre la escena al paradigma antropológico triádico. La convicción que subyace en lo expuesto a continuación será que la manera de encontrar las buenas respuestas dependerá de buena formulación de las preguntas, habiendo aclarado las dudas y las temáticas turbias previas a la apertura de cualquier debate.

\subsection{A términos diferentes corresponderán significados diversos}

La tesis apuntada aquí señala que a sustantivos diferentes conviene aplicar significados diferentes; de hecho, incluso los sinónimos reciben acepciones distintas dependiendo de su contexto y uso. Al tratarse de dos términos tan sensibles en el presente caso, como son el alma y el espíritu, conviene afirmar que una cierta mentalidad diádica ha expulsado al espíritu de un significado propio y determinado, igualándose o, en el peor de los casos, subyugándose al alma.

Dicho sea de paso, cuando aquí se cite el esquema diádico se apunta a la estructura antropológica fundamental de cuerpo y alma. Una formación diádica no debe identificarse inmediatamente con el dualismo, que tiende al desprecio de la dimensión material y física del cuerpo, mientras sobrevalora el alma como parte espiritual, en su extremo angélica, del compuesto humano. En este sentido, movimientos como la gnosis, el catarismo e incluso el jansenismo no dejan de ser frutos concretos del dualismo, desde dónde se han situado histórica y espiritualmente. El actual posthumanismo se puede identificar como un resultado no querido del mismo dualismo, pues se sigue tratando de la negación de la dimensión espiritual, puesto que el alma ha sido relegada a una emergencia de la materia, como fruto del dualismo práctico extremo. No obstante, si bien es cierto que la propuesta proveniente del Magisterio de la Iglesia es de base diádica, en ningún caso quiere ser dualista, sino que más bien se apoya en 
la propuesta aristotélica de Tomás y de su redescubrimiento del hilemorfismo. El aquinate encontró en el planteamiento de Aristóteles la manera de reunir de forma inseparable, al tiempo que inconfundible, el alma y el cuerpo, identificándolos como partes espiritual y corporal física del ser humano. Con esta síntesis, y huyendo de la tentación del dualismo neoplatónico, gnóstico y cátaro, desvirtuaba quizás sin querer y como mal menor, la apuesta del cristianismo por el cuerpo, por la promesa del cuerpo espiritual y por la resurrección corporal, tal y como lo pide la revelación, con el evento de la resurrección de Cristo y las afirmaciones del mismo Pablo (1 Co 15,44). ¡De aquellos polvos, llegaron estos lodos! En todo momento habrá que recordar que el cristianismo apuesta e inventa la naturaleza del cuerpo; ${ }^{18}$ una naturaleza que, en todo caso, queda aún por desarrollar en toda su extensión antropológica, teológica y filosófica, así como su aplicación a todas luces.

A pesar de todo y, sin embargo, habrá que reconocer, y esta es una de las convicciones del autor de la presente aportación, que la estructura diádica cuerpo y alma se decanta por sí misma hacia un dualismo práctico, sin quererlo quizás. Por el contrario, conviene en todo caso revisitar el esquema triádico, considerado aquí como el más original del cristianismo, arrancando en Pablo, Ireneo y Orígenes, como se vienen citando. Dar unos pasos hacia atrás puede ayudar a tomar perspectiva en la contemplación del paradigma antropológico a tomar.

Así, pues, si los términos de «alma espiritual» y «espíritu» se parecen, en cambio, no son, ni representan, ni expresan lo mismo. Fromaget dedica un extenso artículo para hablar de la cuestión y ayudar distinguir los ámbitos del alma y del espíritu, en su obra «Dix essais sur la conception anthropologique corps, âme, esprit», ${ }^{19}$ que dejamos aquí citada por ser conveniente considerar, aunque sobrepasa aquí la extensión posible del presente artículo.

\footnotetext{
${ }^{18}$ GESCHÉ, «L’invention chrétienne du corps».

${ }^{19}$ Cf. FromaGET, «Des critères de distinction entre l'âme et l'esprit».
} 


\subsection{Deslizamiento del planteamiento filosófico griego antiguo}

El paradigma diádico afirma que el ser humano se constituye de cuerpo y alma espiritual en una unidad inseparable, aunque se pueda hablar de las diferentes dimensiones humanas. Conviene tener presente algunos matices a considerar en este planteamiento.

Primer matiz. El vocabulario del paradigma diádico cuerpo y alma arranca en Platón, principalmente en sus mitos de la cuadriga y de la caverna. ${ }^{20}$ Se consagra en Aristóteles, y su «Ética a Nicómaco», así como en el tratado «Sobre el alma», ${ }^{21}$ identificando la parte superior del alma como noûs, mente o intelecto, ${ }^{22}$ que no exactamente corresponde con el corazón, ni con el espíritu, ni con el pneuma antropológico de 1Tes 5,23.

El alma no es una entidad simple, para Aristóteles, sino que, compuesta de varias partes, hasta seis, ${ }^{23}$ de entre las que cabe destacar la parte inmortal separable del alma, forma de la materia, ${ }^{24}$ el intelecto superior o nô̂s, ${ }^{25}$ que consiste en una parte llamada divina ya que no pertenece a la materia: exterior, totalmente incorporal, impasible, sin mezcla y fuera del tiempo. Del mismo modo que Platón, Aristóteles distingue perfectamente entre alma y espíritu, identificando la meta de la vida humana como la asimilación a lo divino. ${ }^{26}$ La cumbre hacia la que tiene que encaminarse el ser humano es la vida de Dios, con quien tiene en común la inteligencia, el noûs precisamente. Así, en estos deliciosos términos se expresa en su «Ética a Nicómaco»:

La felicidad exige ocio. Nos esforzamos para disfrutar del ocio y hacemos la guerra para obtener paz. [...] La actividad contemplativa del intelecto parece ser superior a la actividad que conlleva afán. [...] Está claro que una vida de este tipo podría ser demasiado elevada para la

\footnotetext{
${ }^{20}$ Platón, Phaedr. 248 a-c: FBM 250,77-78. Íbid., 249c: FBM 250 (FBMD IX), 80. Íbid., 508d-509b: FBM 263,110-112. Íbid., 274 b-c: FBM 250,114-115. Íd., Tim. 91d - 92b: FBM 305 (FBMD XVIII), 158-160.

${ }^{21}$ Aristóteles, An. II.1, 412a-413a: LAIA 4,73-77.

22 Íd., Eth.nic. X.7,1177 b-1178a: FBM 292,264-266 = BGP II,234.

${ }^{23}$ Íd., An. 431,20-432: LAIA 4,142-143; Íd., An. 433, b2: LAIA 4,148.

24 Íd., Metaph. XII.3: BGP I,386-387.

25 TRESMONTANT, Le problème de l'âme, 109.

${ }^{26}$ Platón, Tim. 76b: FBM 317,137.
} 
condición humana. Mas nadie vivirá así, contando sólo con su humanidad; siendo necesario cuente con lo divino que hay en él; en la medida que lo divino sea superior al que él tiene de compuesto. [...] Si el intelecto [el noûs] es divino en relación al hombre, la vida que está de acuerdo con el intelecto resulta igualmente divina en relación con la vida humana. [...] Tenemos que inmortalizarnos lo máximo posible y debemos intentarlo para vivir de acuerdo con lo mejor que hay en nosotros. A pesar de que en tamaño sea pequeño, en pujanza y dignidad lo sobrepasa todo de mucho. Hasta podríamos pensar que cada uno se identifica con lo que en él hay de mejor, ya que es lo que predomina y sobresale. [...] Lo que es propio de la naturaleza de cada ser es lo más excelente y lo más placentero para cada uno. Esto, para el ser humano, es la vida que está de acuerdo con el intelecto, puesto que lo es por encima de todo. Por este camino, la vida presente se convierte en la más feliz. ${ }^{27}$

No obstante, si bien los datos de la revelación apuntan hacia un estado de comunión con Dios, yendo mucho más allá del noûs, del contacto intelectual entre creador y criatura, ésta entra en la compartición de la propia vida de Dios, tal como sostiene el mismo Cristo: «Quien permanece en mí y yo en él da mucho fruto; fuera de mí no podéis hacer nada» (Jn 15,5). Se trata de lo que afirmarà Atanasio de Alejandría, en la paradosis patrística: «Dios se ha hecho hombre para que el hombre sea Dios. [O bien:] Dios ha venido a compartir la vida humana en Cristo para que el hombre pueda compartir la misma vida de Dios. ${ }^{28}$ Donde queda claro que «compartir la vida» se convierte en algo mucho más completo y complejo que «pensar lo mismo» que Dios. Se trata de la temática de la divinización, conocida como «teosis» desde antiguo. El tratado teológico de la gracia, de hecho situado en el currículo académico teológico como «Antropología II», indica de qué manera esta divinización del ser humano constituye el verdadero objeto de la existencia, en el sí de su propia comprensión y para con su relación con Dios. ${ }^{29}$ Será Tomás de Aquino quien recogerá este pensamiento con un adagio en sabor clásico de la paradosis, «Deus homo factus est ut homo fieret Deus. $»^{30} \mathrm{Y}$ es que fue Tomás, desde el siglo XIII, quien recuperó de hecho los datos de los pensadores griegos y los bautizó, por así decirlo; presentándolos para ser incorporados y reconocidos en el ámbito cristiano. En su discurso viene a afirmar que los

\footnotetext{
${ }^{27}$ Aristóteles, Eth.nic. X.7,1177 b-1178a: FBM 292,264-266 = BGP II,234.

${ }^{28}$ Cf. Atanasio de Alejandría, Inc. 54,3: SCh 199, 458-459.

${ }^{29}$ Para la divinización, conviene referirse a la obra del profesor CAPDEVILA, Liberación y divinización.

30 Tomás de Aquino, «Opusculo 57. En la fiesta del Cuerpo de Cristo, lect. 1-4».
} 
griegos ya decían algo que se podría entender como perfectamente cristiano, haciendo concordar el dato filosófico con el propiamente revelado. Este vínculo, que resulta deslumbrante por sí mismo, en cambio no es exacto, precisamente porque no respeta la mínima triple dimensión humana presentada en los escritos del Nuevo Testamento y simplifica la estructura fundamental humana reduciéndola a una oposición corporal-espiritual, impropia de la noción cristiana. Por el contrario, resulta necesario en todo momento aceptar el dato revelado precisamente como dato, con su propio peso y validez, en equiparación con cualquier otro, teniéndolo presente como criterio a la hora de formular una concepción que implique al ser humano y su destino futuro sobrenatural. Desde este planteamiento, se reconoce que el lenguaje y las categorías utilizadas deben respetar y responder siempre a lo que la revelación aporta, sobre todo a partir de la Escritura. En cualquier caso, los datos de los griegos no son equivalentes a los revelados por la tradición judeocristiana. Así, en consecuencia, todos los datos resultan aceptables, aunque con condiciones de jerarquía y algunas prevenciones. De hecho, si los griegos ya lo hubieran dicho todo, tal y como la escolástica pretendía, entonces no habría sido necesaria la revelación o, como mínimo, ésta habría resultado superflua. En cambio, constituye el criterio y fundamento de toda la teología, tal y como lo reclama el CVII: «Que la teología sea enseñada, a la luz de la fe y bajo la guía del Magisterio de la Iglesia, de tal manera que los alumnos extraigan cuidadosamente de la Revelación divina la doctrina católica.» ${ }^{31}$

\subsection{Exigua tradición del término «alma espiritual»}

Insospechadamente, la terminología sobre el alma espiritual cuenta con un más que escaso siglo de historia. Desde Tomás, la forma concreta para referirse al principio espiritual o divino en la persona era «alma racional». Ni el uno ni el otro no corresponden a la tradición bíblica ni patrística. Este término concretamente no aparece hasta 1931, cuando lo cita por primera vez un documento papal de Pío XI, afirmando que «el hombre se constituye por un alma espiritual e inmortal [...] cuerpo y espíritu.» ${ }^{32}$ En consecuencia, el término de alma espiritual

\footnotetext{
${ }^{31}$ CVII, OT 16: DCVII 498-499.

${ }^{32}$ PIUS XI, Encíclica Divini Redemptoris (19 març 1937): DH $3771=$ AAS 29 (1937) 78.
} 
no será tan importante, ni tan antiguo, ni tan auténtico como podría parecer, sino una categoría forjada por la necesidad de comunicar una realidad en la cultura del primer tercio del siglo $X X$. De hecho, se puede aseverar que el vocabulario y las formas de expresión referentes a la antropología fundamental han ido cambiando y evolucionando a lo largo de la historia, dependiendo de las necesidades, capacidad, receptividad de la población y los retos del momento, si bien el lenguaje del Catecismo continúa hablando en estos términos actualmente. ${ }^{33}$

En cambio, la antropología primera, que se ocupa de la concreción de las categorías fundamentales, no trata de aportar un punto de vista religioso, como suele ocurrir cuando se habla del alma espiritual, sino que pretende contemplar al ser humano en su entereza primaria y multidimensional. De hecho, el mismo término de «alma» ha quedado cargado de una fuerte potencia religiosa, y por tanto confesional, más allá de su contenido estrictamente antropológico. Por esta vía, los antropólogos contemporáneos tienen dificultades para utilizar este término. Sin embargo, la psicología sigue siendo la ciencia del comportamiento, tal y como Aristóteles, el sabio de Estagira, reclamaba. Parece, por tanto, que esta disciplina actualizada se habría apropiado del tratamiento y el estudio del alma humana reducida a fuente del comportamiento. El alma, por este sesgo, deja de ser un término útil y comprensible a primera vista para la dimensión espiritual, en la búsqueda del sentido existencial, de apertura a la trascendencia y al mundo de lo divino. De hecho, es el esquema diádico cuerpo-alma lo que, en su lectura posmoderna ha acabado embotado, porqué ya no habla de la vocación trascendental humana sino únicamente de su aquí y ahora, en la forma del propio comportamiento, convertido en espejo del alma.

La convicción del autor de estas páginas corre en el sentido de que, ante el agotamiento de la terminología diádica cuerpo y alma, como fruto del auge del materialismo monista y de sus implicaciones en la monopolización del alma por parte de la psicología, conviene recuperar la categoría del espíritu: el pneuma de raíz bíblica, que indique la dimensión divina, que permite

\footnotetext{
${ }^{33}$ CEC 364-365.
} 
al ser humano abrirse hacia lo trascendente, el sentido y lo sobrenatural. Un autor de la categoría de Ladaria, en su «Introducción a la antropología fundamental», se reafirma en ese preciso sentido. Por un lado, en el planteamiento diádico de las aportaciones de la patrística, sobre todo de Ireneo, en Orbe y en las aportaciones de Ruiz de la Peña. Por otro lado, postula la validez de la categoría del espíritu, como la más rica y apropiada a la hora de enfocar cualquier planteamiento antropológico de futuro. ${ }^{34}$

\subsection{Primacía del dato revelado en el método teológico}

Como consecuencia lógica de lo que se ha venido diciendo hasta ahora para la metodología en antropología, conviene afirmar que el dato proveniente de la revelación judeocristiana conlleva una pretensión de primacía frente a otros datos válidos y posibles. En efecto, el planteamiento triádico viene a expresarse en el sentido que la aportación propia del cristianismo constituye al hombre en múltiples vertientes y dimensiones, de las que ciertamente hablaban los griegos, aunque todavía no de forma plena. Este planteamiento no resulta de la misma forma en el paradigma diádico, que se traga casi acríticamente lo que pronosticaba Aristóteles. Si Cristo vino, fue para revelar Dios a la humanidad, quedando esta, desde entonces, renovada en lo espiritual. De ahí, la presentación de Pablo en la importante cita de la despedida a los de Tesalónica, nuevamente 1 Tes 5,23.

Hay que reconocer que, si los griegos lo hubieran dicho todo sobre Dios y sobre el ser humano, entonces cabría formularse la pregunta del por qué debería haber venido el Cristo. ¿Para la redención de su pasión, muerte y resurrección? Ciertamente, ¿pero qué es lo que rescata el Cristo: el hombre griego o el bíblico? Si se atisba que el dato teológico no deviene necesario para el pensamiento, como parece reconocer Tomás dejándolo metodológicamente para el final y únicamente como prueba para la verdad filosófica, entonces bastaría con la simple filosofía, con la sola razón desnuda para alcanzar la verdad. En ese supuesto, la revelación se

\footnotetext{
${ }^{34}$ LADARIA, Introducción a la antropología teológica, 85.
} 
convertiría en sobrante. Hoy por hoy, no se puede aceptar un tal planteamiento sin caer en una injusta e impropia marginación de los datos de la revelación judía y cristiana.

Para los pensadores griegos, resultaba impensable que Dios viniera a hacer su estancia en el ser humano, como pide la revelación de Cristo en el NT. Resulta, ésta, la principal aportación neotestamentaria: el ser humano creado a imagen de Dios, conlleva la existencia y presencia de una chispa divina en su intimidad; ni más ni menos que el Espíritu divino en cada criatura humana desde el inicio hasta el fin de su paso por el mundo, como reclama Gn 2,7: Entonces Yahveh-Dios formó al hombre del polvo de la tierra, insufló en sus narices aliento de vida

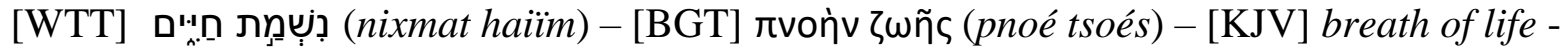

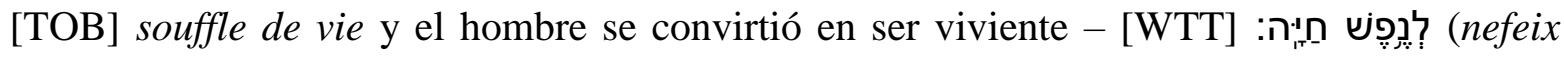

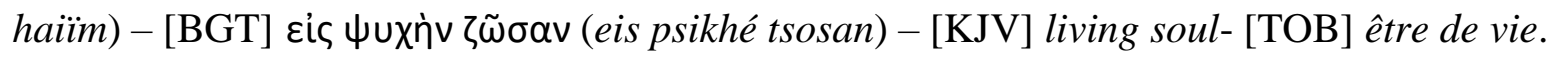

Este nixmat haïm no es otro que el pneuma, la misma prenda del Espíritu Santo depositada por el creador en el hombre, partícula señalada por Pablo a múltiples instancias (Rom 8,23; 2 Co 1,22; 5,5; Ef 1,14). Un espíritu aún incompleto, al cual le queda ser desarrollado, culminado y coronado a lo largo de la vida, tal como el apóstol Pablo lo explica en el capítulo octavo de su Carta a los Romanos, haciendo aparecer en el mismo versículo del espíritu humano, el pneuma, y el espíritu de Dios, destinados a fusionarse (Rm 8,16). De hecho, no es difícil entender que, para un griego resultaba este un planteamiento imposible, impensable y, a fin de cuentas, increíble. Véase, si no, la reacción de los oyentes de Pablo en el discurso del Areópago (Hch 17,16-34). Por lo tanto, no se puede decir que aquella alma planteada por Platón y Aristóteles se pueda identificar directamente con la que ha de recibir el Espíritu Santo divino, sino que debe ser algo diferente. La cuestión metodológica deviene importante, como reclama el CVII:

Las asignaturas teológicas [...] deben extraer cuidadosamente la doctrina católica derivada de la revelación divina.

Los alumnos deben ser formados [...] mediante el estudio de la Sagrada Escritura, que debe ser como el alma de toda la teología; tras la adecuada introducción, deben ser cuidadosamente

Volumen 1. Número 2. Julio - Diciembre 2021 
iniciados en el método exegético, captar los máximos temas de la divina revelación y ser espoleados y alimentados en la lectura y en la meditación diarias de los Sagrados Libros.

La teología dogmática debe estructurarse de forma que primero sean explicados los mismos temas bíblicos; se expondrá a los alumnos tanto lo que los Padre de la Iglesia de Oriente y de Occidente.

A fin de ilustrar íntegramente, en lo posible, los misterios de la salvación, los alumnos aprenderán a penetrarlos más íntimamente con la ayuda de la especulación y a captar sus conexiones, bajo el magisterio de Santo Tomás. ${ }^{35}$

Por lo tanto, la metodología propuesta para la teología, desde 1965, consiste en partir de los datos bíblicos, extraer los principales argumentos y, a posteriori, desplegar las consecuencias con la ayuda de la aportación de Tomás, es decir, de la filosofía, del pensamiento y de la especulación. El recorrido deviene claro, pues: hay que partir de los datos bíblicos, pasar por el Magisterio eclesiástico arraigado en el pensamiento tomasiano, para avanzar a través del diálogo y del debate en el reencuentro con el pensamiento contemporáneo. En este sentido, se define un orden de prioridades: primero la revelación, después el resto de aportaciones, de entre las cuales, las provenientes de la filosofía se ha de considerar preciosa, pero no superior a la primera. Por lo tanto, quien debe llevar el peso verdadero de la cuestión deberá ser, en todo caso, el dato de los escritos revelados, paulinos en este caso: 1 Tes 5,23; 1 Co 15; Rm 8, incluso He 4,12; Gn 1,26-27 y su texto complementario en Gn 2,7; textos que aparecen de todas todas en el desarrollo antropológico fundamental.

Las preguntas de tipo metodológico vienen y vuelven una y otra vez. Si la antropología bíblica habla del hombre triádico y si la teología se debe articular sobre los fundamentos de los datos bíblicos, cabe preguntar ¿por qué en teología sistemática se sigue hablando del paradigma a partir del hombre diádico, cuerpo y alma, cuando ésta en realidad no proviene de una raíz bíblica? ¿Después de los amplios conocimientos adquiridos por los diversos aspectos teológicos, tanto bíblicos como patrísticos, por qué se sigue manteniendo la terminología diádica, cuando hay amplios testimonios en el sentido triádico? No se tiene que olvidar que

${ }^{35}$ CVII, OT 16: DCVII 498-499.

Volumen 1. Número 2. Julio - Diciembre 2021 
«la Palabra de Dios es viva y eficaz, más tajante que espada de doble filo, que llega a dividir el alma del espíritu» $(\mathrm{Hb} 4,12)$. Así, si alguien presentara alguna reticencia para reconocer la distinción entre alma y espíritu, como la Palabra revelada indica, significaría que no ha abundado suficientemente en el estudio y conocimiento de la misma Palabra.

\subsection{Consecuencias de una antropología de matriz diádica}

Por si fuera poco, con esta explanación sobre la conveniencia de la adaptación de la terminología triádica, convendría fijarse en las desinencias prácticas de una matriz de terminología diádica. Es decir, si bien resulta bastante evidente que en la Escritura no aparece la díada cuerpo y alma y sí, en cambio, espíritu, alma y cuerpo, o espíritu y cuerpo, en el lenguaje corriente y académico, se sigue apostando por una formulación diádica, que se desliza indefectiblemente hacia el dualismo. De hecho, las nuevas antropologías, empujadas por los efervescentes y emocionantes avances en los campos de las ciencias positivas, tienden más bien hacia el materialismo monista. Aquellas sostienen que todo es materia, todo lo que existe, lo que se mueve y cambia no deja de contenerse en el ámbito físico, incluidos la mente, el espíritu, los comportamientos sociales, religiosos, culturales, que no dejan de ser materia.

Autores más clásicos como Feigl, Bunge así como otros de producción contemporánea como Rovelli, acaban adquiriendo el convencimiento de que todo se puede explicar a partir del cerebro, en su reducción más material. Feigl proponía una teoría de la identidad de la mente con el cerebro, con sus desinencias, ${ }^{36}$ como el emergentismo, que identifica toda manifestación humana como puramente materia o surgida de ella. Bunge profundiza en esta teoría del materialismo emergentista en la identificación de la mente con el cerebro. ${ }^{37}$ Incluso Eccles, con Popper y su teoría de los tres mundos, identifica cualquier manifestación humana, en su pluralidad y riqueza, como producto de la materia más excelsa y evolucionada. ${ }^{38}$ Por último, Wiener, Mackay o Luís Ruiz de Gopegui serán los representantes de la conclusiva

\footnotetext{
${ }^{36}$ FeIGL, The «Mental» and the «Physical», 54-72, 85, 72.

${ }^{37}$ Bunge, The Mind-Body Problem. A psychobiological Approach, 133.

${ }^{38}$ POPPER - ECCLES, El yo y su cerebro. ECCLES, El misteri de l'home.
} 
identidad del humano con la máquina. ${ }^{39} \mathrm{Si}$ el hombre, en definitiva, por evolución y desarrollo, no es más que materia, si ésta se expresa en manifestaciones excelsas como el arte, el lenguaje, la espiritualidad, no tienen que ser consideradas sino como emergencias de la materia misma. Aún más, si una máquina puede parecerse a un humano, si de un ordenador se puede postular su progresiva identidad en el futuro con un humano, entonces se podrá sostener que el hombre no es más que una máquina muy evolucionada que un día, más allá en un futuro indeterminado, encontrará su total equiparación al de un automatismo perfecto, por muy complejo e insondable que parezca ahora. Para estos autores, pensar deviene un proceso físicoquímico. Sin embargo, pensadores científicos como Carlo Rovelli ${ }^{40}$ huyen de la identificación con la materia. Al contrario, siguiendo la fórmula einsteniana de la equivalencia de la energía con la materia, $\mathrm{E}=\mathrm{mc}^{2}$, propugnan una realidad más dependiente de la energía y de las ondas electromagnéticas que no de la materia propiamente. Es decir que, a fin de cuentas, todo son ondas; hasta los seres humanos. Se trata de un paso más en el discurso científico, que viene a mostrar que éste se encuentra en una constante evolución, todavía en el trabajo de conocerse a sí mismo.

Por lo tanto, en la actualidad, y desde el punto de vista emergentista, fisicalista, materialista o energético, parece que ya no es necesario postular un elemento diferente, como el alma o el espíritu, para explicar los comportamientos humanos. Llegará el día en qué conociendo el cerebro en su constitución física y en su funcionamiento se podrá llegar a comprender de qué forma se toman las decisiones y se pasa a la acción. Desde el punto de vista de la antropología, el reto se encuentra en el campo del monismo materialista. Sin embargo y a fin de cuentas, a un planteamiento de tipo monista materialista como éste, habría que postularle un par de cuestiones.

Primera, si se quiere rechazar a toda costa la dimensión de apertura a Dios y al sentido, entonces cualquier forma de expresarse será insuficiente, sea ésta diádica o triádica: no habrá manera posible de entrar en debate. El cierre conceptual de base continuará y no valdrá ningún

\footnotetext{
${ }^{39}$ RUIZ DE LA PEÑA, «La dialèctica mente-cerebro: entre el monisme y el dualismo», 133-199.

${ }^{40}$ RovelLI, La realidad no es lo que parece. ÍD., Set breus lliçons de física.
} 
argumento. Más bien, cuando se avanza en este campo, se suele quedar atascado en el mismo punto de partida en el que se encontraba, porque los prejuicios suelen ser muy resistentes, por los dos lados, se entiende: el del cristianismo y el del materialismo a ultranza.

Otro punto de vista partiría de la propia de antropología cristiana, que sostiene que el hombre es un ser creado a imagen de Dios, manteniendo su prerrogativa sobre el resto de la creación. Aún más, el dato básico cristiano pide reconocer que, desde el inicio de su creación, lleva en su ser una chispa divina, el nixmat haïm, ${ }^{41}$ que tiene en Dios su origen y su destino (Gn 2,7). Este término difícilmente traducible, se debe comprender, tal como apuntan los Padres del CVII, como el «germen divino - divinum quoddam semen», ${ }^{42}$ es decir, como la chispa o fermento divino. A fin de cuentas, significa que en cada persona, desde que llega a este mundo, radica algo propio de la divinidad, semejante a una presencia, una existencia, en forma de semilla, simiente, germen o fermento. En consecuencia, la categoría «imagen de Dios» de Gn 1,27 señala la presencia de ese quoddam divino en el hombre y no sólo un símbolo o una voluntad. Al contrario, se tratará más bien de una realidad que espera crecer, desenvolverse, ser completada y finalizada completamente por la infusión total del Espíritu divino en el ser humano, como señala Rm 8,16. Ahora bien, según los principios de encarnación, el hombre sólo participará parcialmente, por sus condiciones de mortalidad y pecaminosidad, en esta comunión del Espíritu con el pneuma, que tan solo llegará a su plenitud en vencer y traspasar de este mundo a la eternidad divina. Si bien el hombre no puede pretender poseer Dios, ni su propio Espíritu, sí en cambio Dios puede llegar a poseer al humano, en la medida que éste desee participar de la obra redentora y salvadora universal (1 Tm 2,4).

\subsection{Tarea en los hombros de la Iglesia}

La defensa y difusión del paradigma antropológico se ha encontrado de siempre en las manos de la enseñanza de la Iglesia, a través de sus seminarios y escuelas de teología y, en menor medida, a cargo de otras instituciones de tipo universitario. Pero hay que reconocer que quien

\footnotetext{
${ }^{41}$ CVII, OT 16: DCVII 498-499.
}

${ }^{42}$ Cf. GS 3,2: DCVII, 728-729.

Volumen 1. Número 2. Julio - Diciembre 2021 
más se ha apresurado a acuñar un lenguaje en torno a la estructura ontológica del ser humano ha sido desde siempre la Iglesia Católica de Occidente; troquel ya cristalizado de forma preeminente en la página del $C E C$ citada. Siendo cierto que, en la construcción y difusión del paradigma, han intervenido otros actores, notablemente Descartes al inicio de la Ilustración, o bien los mismos pensadores de la sospecha, como Feuerbach, Marx o Nietzsche, incluso Freud. Éstos se han movido en el ámbito cultural occidental, surgidos del monoteísmo judeocristiano, y marcados, ya sea a favor o en contra, por la doctrina de la Iglesia, mayormente protestante en estos autores. A estos hay que añadir los de la segunda mitad del siglo XX, con el auge del monismo materialista, como Feigl, Bunge o Ruiz de Gopegui, presentados brevemente, y muchos otros que han seguido su estela hasta llegar, últimamente, a Y.N. Harari, el cual resulta como una potente muestra del posthumanismo de estos albores del siglo XXI. ${ }^{43}$ Además, conviene tener presente que todos los casos citados tienen en común haber surgido del monoteísmo de raíz occidental.

Resulta necesario calibrar la responsabilidad de la Iglesia en la enseñanza del paradigma antropológico. El hecho de defender y predicar una ontología diádica, que fácilmente se encontró declinando hacia el dualismo, ha engendrado modernamente una corriente materialista, con la negación de la dimensión espiritual y trascendente, tanto en el ámbito público como privado de la persona; llegando el posthumanismo hasta el límite de negar la dignidad humana. Desde el momento en que no se asienta el dato bíblico como válido para el discurso científico, deviene superficial y banal la afirmación que el hombre es creado a imagen de Dios, que lleva en su interior un misterio de raíces profundas, que está llamado a la eternidad y a la eterna comunión con su propio creador. Por lo tanto, la Iglesia necesita reponerse para valorar la actual deriva antropológica. De hecho, se ha llegado a este punto después de siglos tutelando la enseñanza, estudio y difusión del paradigma diádico. Éste, conviene reconocer que ha tocado techo, agotando sus posibilidades de articulación antropológica ante los retos de la modernidad. En cambio, existe una nueva formulación y un nuevo impulso para alcanzar la verdad del hombre por parte del Magisterio, empezando por

\footnotetext{
${ }^{43}$ HARARI, Homo Deus. Una breu historia del demà; CASTELLET I SALA, «Íd. o l’home creat a si mateix.»
} 
los teólogos de la antropología. Como sucede en muchos casos, y a pesar de la debilidad actual de falta de predominio social, la Iglesia continúa luciendo como el faro de la conciencia social y metafísica. Por lo tanto, si no emprende en sus manos esta tarea, nadie lo hará por ella o, peor aún, continuará la deriva de la ontología, negando a la práctica la dignidad humana.

\subsection{Nueva oportunidad para la antropología triádica}

En este sentido, hay que retroceder dos pasos atrás, para ir a buscar el esquema antropológico original, de raíz triádica, que puede ayudar a rehacer el camino y a redescubrir la auténtica imagen del hombre, en su entereza y múltiple dimensionalidad, más allá del monismo, del materialismo o de la anulación de su dignidad intrínseca. Por este motivo, a la categoría de «alma espiritual» le falta no sólo la raíz bíblica sino hasta la tradición antigua en la enseñanza de la Iglesia. En cambio, la categoría «espíritu», mucho más adecuada, en el seno de una comprensión ternaria, puede abrir nuevos caminos y posibilidades. Mi tesis doctoral lleva precisamente el título, nada holgado, de «antropología primera triádica». Es decir, que lo que se ha tratado de responder ha sido en el sentido de sentar las bases para la posibilidad de un lenguaje propicio en forma triádica, de espíritu, alma y cuerpo. El trabajo presentado así, como lo que resta de antemano a realizar, debe ponerse en sintonía y continuidad de los grandes autores precedentes, como Ruiz de la Peña, Berzosa, Castro Campolongo o el mismo Ladaria, tan sólo por poner algunos ejemplos cercanos. De todos modos, y desde el punto de vista de la tesis desarrollada, tratándose de antropólogos diádicos que no dualistas, sus planteamientos quedan como base de estudio para el progreso de este tratado.

\section{Una docena de ítems para una antropología en clave «espíritu»}

A modo de amplia conclusión, y remontando a la cuestión que ha motivado el presente artículo, deviene necesario responder a la cuestión de si la terminología de «alma espiritual»

puede continuar articulando la ontología ante su evidente agotamiento. O bien, si por el contrario, no tiene que dar ya el paso de relevo a la del «espíritu», para poder elucidar una

Volumen 1. Número 2. Julio - Diciembre 2021 
articulación más precisa de la actual antropología. Sin embargo, y después de recorrer todas las fuentes y la multiplicidad de autores que se han presentado, conviene concluir que el paradigma de la antropología diádica se revela como desfasada por varias razones que, seguidamente, serán explicadas.

La categoría de «alma espiritual» no responde a la terminología bíblica. En los tratados académicos de antropología se puede comprobar cómo primero se da una vistazo al esquema bíblico, de base triádica, pero luego este esquema no tiene continuidad en el resto de desarrollos. ${ }^{44}$ Parece como si se menospreciara el esquema triádico, negándole cualquier validez para la antropología primera, la que se encarga de dilucidar la terminología, y se acabara continuando con lo que se ha hecho siempre, que no es otra cosa que seguir con el esquema platónico dual proveniente del tomismo, pasado por la neoescolástica. Además, cualquier intento de dar una alternativa a esta escenificación a menudo es considerado como un ataque a la Tradición de la Iglesia, cuando al contrario se intenta responder a la terminología más auténtica.

La antropología diádica no puede responder a los retos actuales del pensamiento moderno, con respecto al materialismo monista y al posthumanismo, porque, a fin de cuentas, cae en otro error, como es el dualismo y su polarización antropológica cuerpo y alma. En efecto, el fruto no querido del paradigma diádico es la identificación únicamente del alma como aquella parte creada por Dios en la imagen y semejanza, como así lo explica Tomás. Por el contrario, el cuerpo se deja como la materia impura e imperfecta que debe ser asumida por el alma, de alguna manera metafísica, pero sin real reconocimiento en la obra de la salvación. ¿No está aquí cayendo en el mismo peligro que alertaba Ireneo contra los gnósticos de su tiempo? Una vez más, el lenguaje diádico acaba dando a luz una concepción dualista. En realidad, no se acaba reconociendo el cuerpo como creado por Dios como imagen y semejanza cuando, de hecho, el relato bíblico habla de esta manera tan corporal, física y material (Gn 2,7). Dios crea al ser humano con sus manos, que no son otras que el Hijo y el Espíritu Santo, como explica

${ }^{44}$ Autores como LADARIA, Introducción a la A.T. LORDA, A.T., RUIZ DE LA PEÑA, Imagen de Dios. 
Ireneo. Lo primero que crea es su cuerpo, su dimensión material y física surgida de los limos de la tierra, tal y como explica el mismo Ireneo y comenta Orbe: Mediadora entre el espíritu y el cuerpo, el alma recibe la semejanza en bien de la carne. El ser humano se parece a Dios en su cuerpo. Tal como Cristo fue glorificado por el Padre en la carne. Apenas tendría sentido retener la similitud en el alma. El trabajo de la humana santificación sería pobrísimo, cuando no nulo del todo, si sólo la psique debiera parecerse a Dios. Simple y uniforme, se santifica en un instante, y sin trabas para llegar hasta Dios, conseguiría de golpe la justa medida, con la unidad del espíritu. ${ }^{45}$

Después, produciendo la conmixtión del alma con el pneuma, la insufla en el cuerpo creado. Así, todo el compuesto humano se reconoce como tomando su origen en Dios: cuerpo, alma y espíritu.

Dios sea glorificado en su criatura que, por su bondad, ha hecho semejante a él, y conforme a la imagen de su Hijo. Ya que el hombre, y no sólo una parte [fit homo secundum similitudinem Dei, sed non pars hominis], se hace semejante a Dios (Gn 1,26), mediante las manos de Dios, esto es por el Hijo y el Espíritu. Así, el alma y el espíritu pueden ser partes, pero no el todo; sino que el humano perfecto consiste en la mezcla y unión del alma que recibe el Espíritu del Padre, y mezclada con ella la carne, que ha sido creada según la imagen de Dios [perfectus autem homo commixtio et adunito est animae assumentis Spiritum Patris et admixtae ei carni quae est plasmata secundum imaginem Dei. $]^{46}$

Tan sólo una explanación del proceso originario del ser humano, que contemple y reconozca su pluridimensionalidad, surgida de las mismas manos del creador, con lo que sugiere de su implicación, puede acabar dando la verdadera dignidad a la humanidad del ser, para afrontar los retos que se le plantean y huir de los reduccionismos y materialismos. Así, el ser humano

\footnotetext{
${ }^{45}$ ORBE, Antropología de San Ireneo, 129.

${ }^{46}$ Ireneo de Lyon, AH V.6, 1a: SCh 153, 72-75. Se ha dejado aquí expresamente el término espíritu en minúscula, mientras que en el latín original de $\mathrm{SCH}$ lo pone en mayúscula. De hecho, y por el sentido del texto se puede poner en las dos formas, ya que está hablando del espíritu en él, que conforma el pneuma humano, por la infusión del Espíritu divino. Sea como sea, se puede debatir donde poner la minúscula o mayúscula, pero lo que queda muy claro es que se hace necesario combinar ambas formas para recoger el pensamiento y la antropología fundamental de Ireneo de Lyon.
} 
se convierte en lo que se piensa de él; porque primero viene la idea y, a posteriori, se convierte en realidad, tal y como reclamaba el pensador tomista y obispo vicense Torras y Bages (+1916): «La vida de cada cual depende de la idea que de ella se tiene; de manera que las ideas hacen al hombre y, según ellas, el hombre es.» ${ }^{47}$

Con tal de romper el círculo vicioso que corre desde el paradigma diádico al dualismo, pasando a la negación de la dimensión trascendente y, finalmente, a la negación de la dignidad humana, conviene retroceder para tomar impulso. En efecto, es necesario poner todo lo aprendido en crisis, desaprender, es decir reformular los principios volviendo a las fuentes para reconocer la necesidad de articular una antropología triádica, de base bíblica y patrística, imprescindible para fundamentar con alguna garantía de solidez una ontología sólida de futuro. Volver a los principios era lo que hizo Orígenes, precisamente con su «Pery Arkhon», ya citado. ${ }^{48}$

«Alma espiritual» identifica a una terminología relativamente reciente, acuñada en el siglo XX, repescada de las fuentes rabínicas del siglo I. Por tanto, se trata de una invención moderna para la ocasión, para poder superar la terminología tomasiana de «alma racional», careciendo ambas de fundamento bíblico. Esta última fue la categoría usada por la Iglesia, verdadera maestra en la materia, para hablar del hombre durante seis largos siglos. Cuando esta terminología aristotélica y tomista se reveló agotada, entonces apareció una nueva forma para tratar de actualizar el discurso: ya no se trataba de basar la originalidad del ser humano en la razón sino en su condición espiritual. Pero aún no se retornó a la antropología bíblica, seguramente porque no había aún llegado el momento, no había madurado suficientemente la cuestión y los conocimientos bíblicos se mantenían como en una segunda categoría, hasta tachados de sospechosos ante el avance del protestantismo de raíz bíblica, precisamente.

En efecto, alma y espíritu, a pesar de parecerse, no son lo mismo. En el Evangelio, Jesús no entrega el alma, sino el espíritu (Jn 19,30 y par.). En ningún lugar de la Biblia no aparece la

\footnotetext{
47 TORRAS I BAGES, Obres completes. VI: 103.

${ }^{48}$ Cf. supra npp 2. Orígenes, Sobre les principios $=P A$.
} 
expresión «cuerpo y alma» si no es para referirse a la humanidad incompleta. Con mucho, aparece la expresión «hombre de carne y sangre» (Mt 16,17; Ga 1,16). Los significados de los dos términos, si uno se aproxima a los datos bíblicos, se diversifican y acaban expresando mejor la riqueza de la realidad del ser humano.

Llegados al siglo XXI, con todo el resto de debate antropológico y científico positivo que hay en la actualidad, conviene devolver la articulación y significados propios al lenguaje, categorías y pensamiento expresados, siguiendo el cuño bíblico, tal y como pide el CVII. Si no se articula de esta manera, no se llegará nunca al fondo de la cuestión, ni con reales posibilidades de enfrentarse con garantías a las diversidades de enfoques de las nuevas antropologías cargadas de peligros negacionistas, como son las posthumanistas. En lugar de plantear la temática con las categorías adecuadas, se seguirá sirviendo de aquellas de cuño diádico, que se han revelado como fuera de lugar, obsoletas, con fundamentos desplazados, no arraigados en la roca bíblica y patrística, sino en las arenas de la filosofía de cuño neoescolástico; vías que se revelan agotadas a la hora de entablar diálogo con el mundo de la ciencia y de la cultura contemporáneas.

Este último constituye el punto crucial, sin duda, para que un debate de apariencia terminológico, que podría parecer vano y superficial, en cambio revista una intensa importancia. Puesto que el debate esbozado aquí se mueve en el ámbito del discurso, conviene reafirmar como las palabras sí son importantes, no tanto como etiquetas, porque no se trata de un debate nominalista, sino de contenidos y de realidades.

En el campo de las ciencias humanas, el siglo XX ha visto desplegar a la psicología y la psiquiatría, con sus múltiples variantes y aplicaciones educativas, sociales, integrativas personales. Son éstas las que reclaman la atención del alma, dado que se trata de interaccionar con pensamientos, ideas, sensaciones, sentimientos, pasiones, instinto, memoria, inteligencia y voluntad. Si el alma se convierte en la materia formal propia de estas ciencias de la modernidad, ¿entonces qué queda para la teología, la espiritualidad, la religión, la Iglesia, la oración, la liturgia o el sentido vital? La respuesta correcta es el espíritu, la puerta 
antropológica para entablar la conexión humano-divina, puesto que se trata de la chispa existente en el ser humano, depositada ahí por el creador desde el mismo origen (Gn 1,26).

Por este motivo, en una concepción diádica, si se afirmara que el hombre sólo es cuerpo y alma, entonces la dimensión espiritual quedaría expulsada, tal y como tiende a suceder en el mundo contemporáneo. El espíritu tiende a ser considerado como un estorbo, como un bibelot con el que no se sabe muy bien qué hacer, que estorba; como mucho una afición privada y, a fin de cuentas, prescindible, por mucho que no sea así. ¿Y qué se hace con los estorbos? Pues se quitan de delante, se apartan y se tiran. La presentación moderna de la cuestión así lo impone. El matiz resulta muy tenue, pero deviene crucial, porque sólo desde el reconocimiento del propio punto de partida resulta posible avanzar. En el caso cristiano, el esquema diádico ha dado ya un muy buen servicio, pero debido a su agotamiento, quizás ha llegado el momento de asegurarle una buena jubilación. Resulta necesario buscar nuevas, aunque antiguas vías de propuesta para que el mensaje antropológico original bíblico se adecúe mejor a las intuiciones evangélicas, que hablan en si de una verdadera y vital interacción entre la humanidad para con Dios, desde el inicio de la su existencia, expresada en su propia creación, descrita en Gn 1,27 y $2,7, \tan$ bellamente.

Por lo tanto, a la hora de presentar, defender y debatir en torno al modelo de persona humana conviene que, desde el punto de vista cristiano, se afirme la tríada espíritu, alma y cuerpo (1 Tes 5,23) en su entereza. Como ejemplo práctico, conviene fijarse como la civilización occidental, representada muy dignamente por los misioneros en países en dificultades, suelen construir tres edificios representando tres servicios, por este orden: el dispensario médico, la escuela con comedor y la iglesia. Es decir, los ámbitos del cuerpo, del alma y del espíritu, respondiendo a lo que ya afirmaba Ireneo de Lyon, desde el siglo II; que «sin cuerpo no se da la persona; como tampoco no se da sin alma o sin espíritu.» ${ }^{49} \mathrm{El}$ apologeta Justino $(+185)$ remachaba la idea con una afirmación no menos sugerente: «así como el cuerpo constituye el lugar del alma, ésta se dispone como casa del espíritu. ${ }^{50}$

${ }^{49}$ Cf. Ireneo de Lyon, $A H$ V.6, 1a: SCh 153, 72-75.

50 «Resurrectio est carnis quae cecidit. Nam spiritus non cadit. Anima in corpore est, quod sino anima non vivit.

Volumen 1. Número 2. Julio - Diciembre 2021 
En estas afirmaciones cargadas de sabiduría y verdad, situadas al inicio del pensamiento y la vida de los cristianos, se encontraría un nuevo argumento a favor de la estructura triádica. Si bien el paradigma diádico se muestra muy celoso de sí mismo para bloquear el desarrollo de cualquier otra interpretación, en cambio, el esquema triádico resulta más ancho y acogedor, tratándose de un sistema más inclusivo e integrador. No se trata de añadir un parche a un esquema embotado sino de plantear un nuevo planteamiento. A primera vista, resulta bastante evidente que el esquema ternario es más completo, inclusivo y amplio, porque actúa con amplitud, reconociendo e incluyendo la pluralidad, diversidad e incluso complejidad de la realidad.

En definitiva, la sociedad occidental, encabezada por el Magisterio eclesiástico, cuenta con setecientos años de discurso diádico; discurso surgido de Tomás, continuado por los movimientos intelectuales de la escolástica y la neoescolástica. ¿Quién se atreve a cuestionar esta historia reciente y afirmar que las fuentes estén ya agotadas? Quien lo haga tendrá que enfrentarse a múltiples intereses, inercias, perezas y desidias de todo tipo, pero a pesar de todo habrá quien se atreva a proponer a las nuevas generaciones una antropología sólida, que no se marchite ante el primer obstáculo que entorpezca a la humanidad en su peregrinación hacia la vivencia y las experiencias de la verdad, el bien y la belleza, signos inequívocos de los atributos de Dios.

Corpus, anima discedente, non est. Nam domus est animae corpus, et spiritus domus anima. Tria haec in iiis, qui sinceram spem et fidem minime dubiam hauberit in Deo, salvabuntur.» Justino, Fr. 595, X: PG 6, 1589-90.

Volumen 1. Número 2. Julio - Diciembre 2021 


\section{Abreviaturas utilizadas}

AAS Acta Apostolicae Sedis. Roma: 1909-.

AH Ireneu de Lió, Adversus Haereses.

A.T. Antropología teológica

BCN Barcelona

BGP Biblioteca de Grandes Pensadores. Madrid: Gredos.

CEC Catecismo de la Iglesia Católica, 1992.

CVII Concili Vaticà II, 1962-65. Las abreviaturas de sus documentos según costumbre.

DCVII CVII, Constitucions, decrets, declaracions. Edició bilingüe. BCN: 2003.

DH DENZINGER-HünERMANn, El magisterio de la Iglesia, ${ }^{38} 1999$.

FBM Colección de la Fundación Bernat Metge. BCN. Edición griego-catalana de los textos clásicos.

FBMD FBM - Diálogos de Platón.

GCS Die griechischen christlichen Schrifsteller der ersten drei Jahrhunderte.

LAIA Editorial i colección de textos filosóficos, BCN.

PG Migne, J., Patrologia Graeca.

RCatT Revista Catalana de Teologia, Barcelona.

SCh Sources Chrétiennes, París. 


\section{Conclusiones}

Históricamente, más allá de problematizar sobre los diversos significados etimológicos que se enmarcan en el concepto de "valor" como categoría, la discusión de los valores se ha centrado en considerar, si éstos permanecen, cambian o se resignifican; ya que, factores como el contexto social, cultural, político o religioso, influyen sobre la percepción que se construye alrededor del concepto y la configuración de las prácticas sociales que reviste.

En razón de lo anterior, los valores siempre resultan problemáticos y complejos, en la medida en que están determinados por cada micro contexto cultural. En ese sentido, los distintos campos del conocimiento han realizado abordajes que pasan por la filosofía, la antropología, la sociología y la religión desplegando una serie de teorías que se complementan interdisciplinariamente. Consuetudinariamente, la educación ha sido considerada como un aparato ideológico de reproducción social y del estado, que además como institución legitimadora ha influido en la formación, conservación y resignificación de determinados valores.

Teniendo en cuenta las consideraciones anteriores, éste estudio respondió a los objetivos de la siguiente manera:

Se concluye que la percepción de los estudiantes entrevistados en los dos colegios está relacionada con procesos de subjetivación; entiéndase la categoría "subjetivación" como expresión de procesos de concientización grupales donde están involucrados los sujetos que construyen determinadas visiones del mundo, muchas veces, contraria a la heredada hegemónicamente, que al mismo tiempo son problemáticos (Touraine, 2012). En ese orden de

ideas, se encontró que los estudiantes, como parte de sus dinámicas de subjetivación y conciencia crítica, procesan la información que reciben y la reevalúan dependiendo de sus intereses/motivaciones que los muevan en el entorno escolar. 
De otra parte, una emergencia significativa está relacionada con la concepción de la categoría "valor" en dos ámbitos éticos que configuran al mismo tiempo determinados comportamientos: el ámbito de la ética teleológica (Pérez, 2001) y el campo de la ética autotélica. La primera, configura la concepción de los valores dentro del cumplimiento de deberes con el fin de ganar un premio o evitar un castigo, característica que históricamente ha sido poderosa en la escuela tradicional cuando se trata de "educar en valores". En el caso de la población objeto de este estudio, un significativo número de ellos configuran sus conductas basados en la norma, con el propósito de evitar el llamado de atención de un coordinador o un docente y evitar un castigo o, en su defecto, una felicitación.

Mientras que la segunda; es decir, la configuración de valores a través de una ética autotélica (Csíkszentmihályi, 2011) o de la gratificación en el hacer, está asociada a la concepción y configuración de los valores desde sentimientos y emociones que producen bienestar en los sujetos estudiantes en el cumplimiento de las tareas y responsabilidades que surgen en la vida cotidiana y que se direccionan desde distintas fuentes, ya sean profesores, líderes estudiantiles o directivas. En este sentido, un grupo de estudiantes también perciben que algunos valores que la institución les ofrece como: la formación en filas en la mañana, el deber de usar el uniforme, la exigencia académica, no fumar en sitios cerrados, no robar, llegar temprano a clase, manejar los conflictos a través del diálogo, entre otros, les producen gratificación por cuanto no representan dispositivos de presión y de control que generen resentimientos o resistencias significativas.

Por otro lado, los estudiantes les dan sentido y representación a determinados valores, atendiendo en principio a dos factores; en primera medida, éstos encuentran que el escenario del descanso es un nicho espontáneo de expresión más "auténtica" de determinados valores que les permiten construir relaciones asociadas, en donde participan también profesores. En este sentido, las relaciones cara a cara (Heller, 1967) generan puentes de comunicación en las cuales se manifiestan valores como la espontaneidad, la amabilidad, la alegría y en general la gratificación de ese encuentro que configura lo que Echeverría (2010) denomina "un tiempo kairótico"; es decir, un momento temporal y espacial de disfrute. 
En segunda instancia, existe una tendencia significativa a jugar con la categoría "valor" de acuerdo con las necesidades, intereses y motivaciones que se producen en el contexto; este comportamiento de los estudiantes refleja de alguna manera la tesis de Elster (2010) que sostiene que con frecuencia los seres humanos suelen invocar una norma o un valor para defender un autointerés y de esa manera adaptarse a cada momento según le convenga, lo cual, eventualmente, les generaría menos dificultades dentro del círculo de interacción.

En términos más amplios se concluye también un hecho significativo: la población objeto de estudio hace una relación de su formación con el papel que cumplen las instituciones educativas en dos sentidos. En primera medida, los estudiantes reconocen en estos colegios que representan la institucionalidad - la intención de forjar unos determinados "valores" desde la apuesta de un Proyecto Educativo Institucional con unos fines específicos. No obstante, como segundo aspecto, al mismo tiempo, otro grupo significativo - incluyendo algunos profesores que lo manifestaron en las entrevistas a profundidad -, considera que existe una contradicción marcada entre los objetivos teóricos propuestos en el Proyecto Educativo Institucional y algunas prácticas de la vida cotidiana que generan determinadas rutinas de vigilancia y control. Este comportamiento institucional manifiesta lo que algunos autores reconocidos en Colombia, Aguilar y Betancourt (2005); Gómez (2005) y Herrera, Infante, Pinilla y Díaz (2005), definen como la reproducción del sistema político patriarcal en el sistema educativo por cuanto reflejan las continuas contradicciones entre los ideales que proponen en sus discursos las escuelas y las prácticas educativas de la vida cotidiana.

Otro aspecto que se logró determinar es que los estudiantes construyen y deconstruyen los valores de acuerdo con las experiencias de la cotidianidad en los distintos escenarios de interacción, lo cual genera en ellos una actitud crítica que les permite resignificar los valores y sus prácticas. En ese sentido, en el proceso de socialización secundaria (Berger y Luckmann, 2003) los individuos que comparten las experiencias cotidianas experimentan ciertos estadios espontáneos de la formación de su conciencia crítica que va evolucionando, y que está asociada a la percepción de la categoría "valor" en sus distintas manifestaciones. 


\section{Referencias}

Acarín Tusell, N., El cerebro del rey: vida, sexo, conducta, envejecimiento y muerte. BCN: RBA $^{2} 2001$.

Armstrong, D.M., A Materialist Theory of the Mind. Londres, 1968.

Bostrom, N., «A history of transhumanist thought» Journal of Evolution ant Technology 14 (2005), 1-25.

Bunge, M., The Mind-Body Problem. A psychobiological Approach. Oxford: 1980, IX.

Capdevila, V.M., Liberación y divinización del hombre: la Gracia. 2 vols. Salamanca: Sec.Trin 1984-1994.

Castellet i Sala, J., Esperit, anima i cos: antropologia primera triàdica seguint Michel Fromaget. Tesi de doctorat en teologia. En-4. Barcelona: FTC 2016.

— Íd., excerpta. Publicació parcial de la tesi doctoral (Tesis FTC 58) BCN: AUSP-FTC 2016.

—, «Homo Deus o l'home creat a si mateix, de Y.N. Harari. Anàlisi crítica d'un assaig d'antropologia posthumanista» Lletres de Filosofia i Humanitats 9 (2017) 38-67 = [en línia] [consulta: 19/12/20] 〈http://raco.cat/index.php/LletresFilo/issue/view/24560/showToc〉

—, «Esperit, ànima i cos. Introducció a l'antropologia primera triàdica» RCatT 42/1 (2017) 171-195 <https://www.raco.cat/index.php/index/search/authors/view?firstName=Jordi\&middleName $=\&$ lastName $=$ Castellet $\% 20 \mathrm{i} \% 20$ Sala\&affiliation $=\&$ country $=>$ [en línia] [consulta: 19/12/20] —_, El pes de l'ànima (Déu per a pensar 4) Ontinyent: El Toll 2019. Colección de cuatro volúmenes miscelánea de artículos en torno a los Evangelios y las cartas de san Pablo.

—, «ordi Castellet i Sala» Artículos académicos en línea <https://url.academia.edu/JordiCastelletiSala> [en línia] [consulta: 19/12/20]

- «Arxiu de notícies publicades» artículos de opinión en prensa <https://el9nou.cat/autor/jordicastellet/ > [en línia] [consulta: 19/12/20]

—, «Articles d'opinió »<https://www.naciodigital.cat/osona/opinio/autor/357/jordi- 
castellet-sala> [en línia] [consulta: 19/12/20]

Eccles, J.C., El misteri de 1'home. Conferències Gifford. PU Edimburg 1977-1978. BCN: J.E. Jarque 2008.

Feigl, H., The «Mental» and the « Physical». Minneapolis ${ }^{2} 1967$.

Fromaget, Michel, Corps, âme, esprit (Question de) Gordes : Albin Michel 1991.

—, «Des critères de distinction entre l'âme et l'esprit» en ÍD., Dix essais sur la conception anthropologique «corps, âme, esprit» (Culture et cosmologie) París: Harmattan 2000, 117143.

Gesché, A., «L’invention chrétienne du corps» en Le corps chemin de Dieu. París: Cerf 2005, 220, 33-75.

Harari, Y., Homo Deus. Una breu historia del demà. BCN: 622016.

Jacquemin, D., Quand l'autre souffre. Éthique et spiritualité. Brussel·les: Lessius 2010.

——, «Directives anticipées et récit de vie» RTL 48 (2017) 64-84.

Ladaria, L. Introducción a la antropología teológica (Int.estudio teolog. 8) Estella: Verbo Divino 1993.

Lorda, J.L., Antropología teológica (Manuales ISCR 7) Pamplona: UN 2016, 220.

Nouwen, H., Prendre soin les uns des autres. Une spiritualité du «care». París: Salvator 2012.

Orbe, A., Antropología de san Ireneo (BAC 286) Madrid: Católica 1969.

Popper, K.y Eccles, J.C., El yo y su cerebro. BCN: 1980.

Rovelli, C., La realidad no es lo que parece. La estructura elemental de las coses. BCN: Tusquets 2015.

— Set breus lliçons de física. BCN: Anagrama 2016.

Ruiz de la Peña, J., «La dialèctica mente-cerebro: entre el monismo y el dualismo» en ÍD., Las nuevas antropologías. Un reto a la teología (Punto Límite 17) Santander: Sal Terrae 1983, 133-199.

— Imagen de Dios. Antropologia teológica fundamental (PT 49) SDR: SalT 1988.

Tomás de Aquino, «Opusculo 57. En la fiesta del Cuerpo de Cristo, lect. 1-4» en Íd., Opuscula Theologica: Litúrgia de les hores segons el ritu romà. 4 vols. BCN: Regina 1981, III: 66.

Volumen 1. Número 2. Julio - Diciembre 2021 
Torralba, F., Humanisme, transhumanisme i posthumanisme. Assaig de discerniment. BCN : Claret 2016.

Torras i Bages, J, Obres completes. 10 vols. (Biblioteca Abat Oliba) BCN: Montserrat 19841994, VI: 103.

Tresmontant, C., Le problème de l’âme. París: Albin Michel 1961. 